\title{
Effects of Circadian Rhythm Disorder on Learning and Memory in Mice
}

\author{
Huang Changquan* and Liu Qingxiu \\ The Third Hospital of Mianyang, China \\ *Corresponding author: Huang Changquan, The third hospital of Mianyang, Sichuan 621000, China
}

Received: 㘹 December 05, 2018

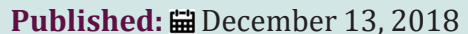

\begin{abstract}
Objective: The change of learning and memory was explored in circadian rhythm disorder mice induced by irregular light/ dark cycle.

Methods: Mice model of circadian rhythm disorder induced by irregular light/dark cycle. Twenty-four male ICR mice were raised under different light/dark cycles including LD 12h/12h (Group 1: Normal circadian rhythm group), light 3h next to darkness $5 \mathrm{~h}$ and light $5 \mathrm{~h}$ next to dark $3 \mathrm{~h}$ alternate every other day (Group 2: Circadian rhythm disorder group). The twenty-four ICR mice were randomly assigned to these two groups and feed six months. Each group included twelve. Morris Water-maze task was used as the judging criteria for spatial learning and memory.
\end{abstract}

Result: The learning and memory was significantly decreased in circadian rhythm disorder mice induced by irregular light/ dark cycle $(\mathrm{P}<0.05)$.

Conclusion: Circadian rhythm disorders impaired learning and memory.

Keywords: Circadian Rhythm; Light/Dark Cycle; Learning and Memory; Mice

\section{Introduction}

Circadian rhythm is a kind of biological a biological characteristic, animals' plants and microbes-many cellular are regulated with 24 -h periodicity by endogenous pacemakers or exogenous zeitgeber signals [1-3]. Circadian rhythm is governed mainly by the suprachiasmatic nucleus (SCN) and molecular clock genes, but the molecular mechanisms of circadian rhythm in peripheral tissues are not yet fully elucidated [4-6]. Circadian rhythm disorder is a common symptom of dementia [7-9]. But is it unclear whether circadian rhythms are one of the causes of dementia? [10-12] Memory and learning ability decline is the core manifestation of dementia [13]. This study was to investigate whether circadian rhythm disorder is one of the causes of dementia by observing the learning and memory of circadian rhythm disorder animal models induced by light-dark cycle.

\section{Materials and Methods}

\section{Animals and Experiment Design}

Animals: ICR mice weight 8-10g, were purchased from Chengdu branch of the Chinese Academy of Sciences Co., Ltd., China.

Animal Feeding and Treatment: Twenty-four were randomly assigned to these two groups, each group included twelve mice. These animals were tested in water maze. The light dark cycle time of each group was LD 12h/12h (Group 1: Normal circadian rhythm group), light $3 \mathrm{~h}$ next to darkness $5 \mathrm{~h}$ and light $5 \mathrm{~h}$ next to dark $3 \mathrm{~h}$ alternate every other day (Group 2: Circadian rhythm disorder group). The ambient temperature is controlled $(22 \pm 2)^{\circ} \mathrm{C}$.

Detection of ICR Mice Activity: Isolating ambient noise and lines, free water intake, free feeding, feeding for 6 months. These 
ICR male mice and raised in a temperature-controlled environment $(22 \pm 2)^{\circ} \mathrm{C}$ and with $50-60 \%$ humidity.

ICR Mice Activity Detection Equipment Includes: Environmental condition control box containing runner, infrared detector and data analysis system. The environmental condition control box controls the ambient temperature to $(22 \pm 2){ }^{\circ} \mathrm{C}$, isolates external noise and light, and automatically provides light-dark cycle according to the experimental design. Infrared detection device and data analysis system collect and analyze data separately. The activity of mice was continuously detected, and 1 time were recorded every $3 \mathrm{~min}$.

\section{The Morris Water Maze Test}

The method of The Morris water maze test was reported previously [14-15]. The Morris water maze was conducted in a circular pool $(120 \mathrm{~cm}$ in diameter and $45 \mathrm{~cm}$ in height $)$ with a featureless inner surface. The water-maze tank was placed with four external visual cues and filled with water containing a nontoxic white color. The temperature of the water was maintained by 23$25^{\circ} \mathrm{C}$. A white platform $(10 \mathrm{~cm}$ in diameter and $30 \mathrm{~cm}$ in height) was placed in one of the quadrants with equal area and submerged $2 \mathrm{~cm}$ below the water surface. During each trial session, the escape latency time spent to find the hidden platform was monitored by a video tracking system. During the four subsequent days of training the mice were given three trials per day with the submerged platform in the pool. When the mouse located on the plated platform, it was allowed to remain on it for an additional $10 \mathrm{sec}$. If the mouse did not find the hidden platform within $120 \mathrm{sec}$, the mouse was guided to the platform and permitted to remain on it for an additional 10sec. On the last day, the hidden platform was removed from the watermaze tank and probe test was performed. Mice were allowed to swim for $90 \mathrm{sec}$ and the staying time in the maze quadrant where the platform had previously been located was recorded.

\section{Data Analysis}

The data were reported as means \pm SE. Bonferroni t-tests was used to analyze data. The overall level of statistical significance was $\mathrm{p}<0.05$.

\section{Results}

The activity of the mice decreased in the light state and increased in the dark state when the activity cycle was consistent with the light-dark period. The water maze test showed that the time of finding the platform mice in group 2 was significantly longer than that in group 1 (Figure 1).

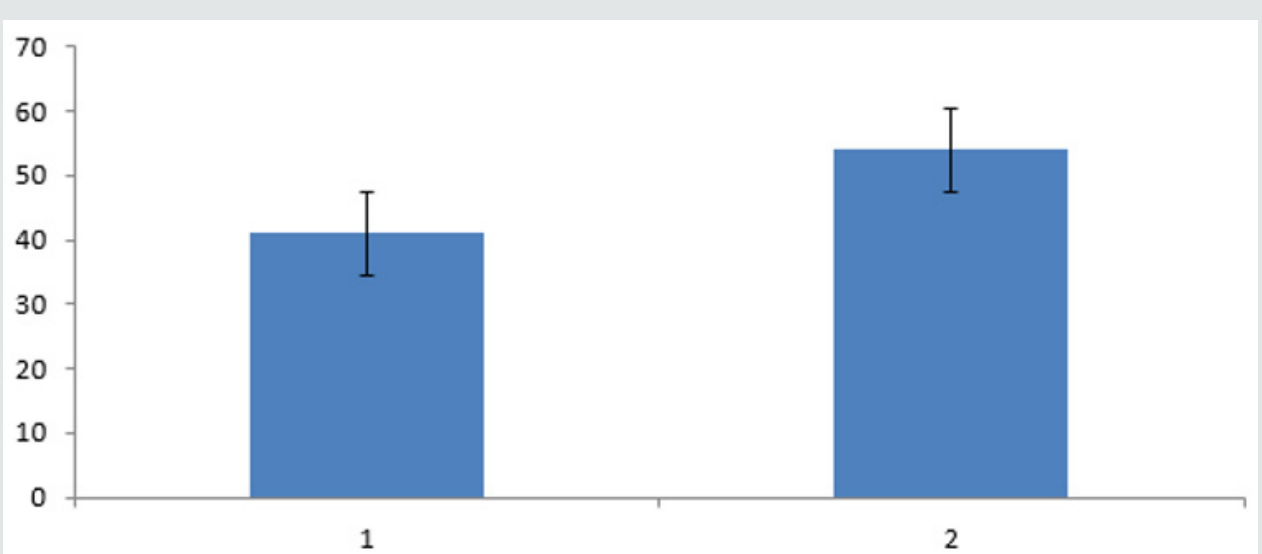

Figure 1: 1) Normal circadian rhythm group. 2) Circadian rhythm disorder group. The figure showed that ability of Mice in group 2 was lower than these in group 1.

\section{Discussion}

The experiment results showed that the learning and memory abilities of circadian rhythm disorder animal models induced by light-dark cycle were significantly decreased. The rotation of the earth formed living environment cycle about 24 hours, including light/dark cycle. As a result, the earth's organisms produce circadian rhythms. The circadian rhythm of organisms is the result of biological adaptation to the environment [16]. 24 hours light/dark cycle was the main cycle, and the formation of circadian rhythms in organisms may be mainly caused by light/dark cycle [17-20]. The circadian rhythm model induced by light dark circulation has become a common method to study circadian rhythm [21-22].
The circadian clock of mammals is located in the suprachiasmatic nucleus of hypothalamus. The circadian rhythm produced by molecular oscillation controls and affects mammalian physiology and behavior through many ways, such as activity, arousal and sleep, hormones and so on. Wakefulness and sleep are controlled by the brain. [23-24] Circadian rhythms can affect arousal and sleep prompting, which can affect brain function, including learning and memory. This study main showed that circadian rhythms can also affect learning and memory abilities.

The essence of the study is the discussion of phenomena and no mechanism for the formation of phenomena. Therefore, this is precisely the limitation of the study. However, this provided a basis for the discussion of mechanism. The study concluded that 
circadian rhythm disorder can lead to impaired learning and memory in animals.

\section{Acknowledgement}

The authors thank the staff of the State Key Laboratory of Management and Control for Complex Systems institute of Automation, Key Laboratory of Chronobiology of Health Ministry in Basic and Forensic School of Sichuan University and the Department of Geriatrics of the third hospital of Mianyang and all study participants (as well as their legal proxies) for their great contributions.

\section{References}

1. Katinas GS, Halberg F, Cornélissen G, Otsuka K, Bakken EE (2005) Time microscopy for all kinds of data including circadian clock biology. Biomed Pharmacother 59(Suppl 1): S20-S23.

2. Zeng L, Wang X, Kang M, Dong F, Yang Z (2017) Regulation of the Rhythmic Emission of Plant Volatiles by the Circadian Clock. Int J Mol Sci 18(11).

3. Oishi K, Yasumoto Y, Higo Yamamoto S, Yamamoto S, Ohkura N (2017) Feeding cycle-dependent circulating insulin fluctuation is not a dominant Zeitgeberfor mouse peripheral clocks except in the liver: Differences between endogenousand exogenous insulin effects. Biochem Biophys Res Commun 483(1): 165-170.

4. Wilkaniec A, Schmitt K, Grimm A, Strosznajder JB, Eckert A (2016) Alzheimer's amyloid- $\beta$ peptide disturbs P2X7 receptor-mediated circadianoscillations of intracellular calcium. Folia Neuropathol 54(4): 360-368.

5. Banks R, Delibegovic M, Stevenson TJ (2016) Photoperiod and Triiodothyronine-dependent Regulation of Reproductive Neuropeptides, Proinflammatory Cytokines, and Peripheral Physiology in Siberian Hamsters (Phodopus sungorus). J Biol Rhythms 31(3): 299-307.

6. Archer SN, Oster H (2015) How sleep and wakefulness influence circadian rhythmicity: Effects of insufficient and mistimed sleep on the animal and human transcriptome. J Sleep Res 24(5): 476-493.

7. Gulia KK, Kumar VM (2018) Sleep disorders in the elderly: A growing challenge. Psychogeriatrics 18(3): 155-165.

8. Hardeland R (2012) Neurobiology, pathophysiology and treatment of melatonin deficiency and dysfunction. Scientific World Journal 640389.

9. Jabbar F, Leonard M, Meehan K, O'Connor M, Cronin C, et al. (2011) Neuropsychiatric and cognitive profile of patients with DSM-IV delirium referred to an old age psychiatry consultation-liaison service. Int Psychogeriatr 23(7): 1167-1174.

10. Slats D, Claassen JA, Verbeek MM, Overeem S (2013) Reciprocal interactions between sleep, circadian rhythms and Alzheimer's disease:
Focus on the role of hypocretin and melatonin. Ageing Res Rev 12(1): 188-200.

11.Zhou QP, Jung L, Richards KC (2012) The management of sleep and circadian disturbance in patients with dementia. Curr Neurol Neurosci Rep 12(2): 193-204.

12. Størmer FC (2015) Is blue light, cryptochrome in the eye, and magnetite in the brain involved in the development of frontotemporal dementia and other diseases? Med Hypotheses 84(4): 379-380.

13. Hohman TJ, McLaren DG, Mormino EC, Gifford KA, Libon DJ, et al. (2016) Asymptomatic Alzheimer disease: Defining resilience. Neurology 87(23): 2443-2450.

14. Bromley Brits K, Deng Y, Song W (2011) Morris water maze test for learning and memory deficits in Alzheimer's disease model mice. J Vis $\operatorname{Exp}(53)$.

15. Weitzner DS, Engler Chiurazzi EB, Kotilinek LA, Ashe KH, Reed MN (2015) Morris Water Maze Test: Optimization for Mouse Strain and Testing Environment. J Vis Exp (100): e52706.

16. Arnold W, Ruf T, Reimoser S, Tataruch F, Onderscheka K, et al. (2004) Nocturnal hypometabolism as an overwintering strategy of red deer (Cervus elaphus). Am J Physiol Regul Integr Comp Physiol 286(1): R174181.

17. Polidarová L, Houdek P, Sumová A (2017) Chronic disruptions of circadian sleep regulation induce specific proinflammatory responses in the rat colon. Chronobiol Int 34(9): 1273-1287.

18. Obi Ioka Y, Ushijima K, Kusama M, Ishikawa Kobayashi E, Fujimura A (2013) Involvement of Wee1 in the circadian rhythm-dependent intestinal damage induced by docetaxel. J Pharmacol Exp Ther 347(1): 242-248.

19. Anderson G, Beischlag TV, Vinciguerra M, Mazzoccoli G (2013) The circadian clock circuitry and the AHR signaling pathway in physiology and pathology. Biochem Pharmacol 85(10): 1405-1416.

20. Donner NC, Montoya CD, Lukkes JL, Lowry CA (2012) Chronic noninvasive corticosterone administration abolishes the diurnal pattern of tph2 expression. Psych neuroendocrinology 37(5): 645-661.

21. Beersma DGM, Gargar KA, Daan S (2017) Plasticity in the Period of the Circadian Pacemaker Induced by Phase Dispersion of Its Constituent Cellular Clocks. J Biol Rhythms 32(3): 237-245.

22. Eynan M, Biram A, Mullokandov M, Kronfeld Schor N, Paz Cohen R, et al. (2017) The transition from day-to-night activity is a risk factor for the development of CNS oxygen toxicity in the diurnal fat sand rat (Psammomys obesus). Chronobiol Int 34(5): 578-586.

23. Kim JH, Duffy JF (2018) Circadian Rhythm Sleep-Wake Disorders in Older Adults. Sleep Med Clin 13(1): 39-50.

24. Chang WP, Lin CC (2017) Changes in the sleep-wake rhythm, sleep quality, mood, and quality of life of patients receiving treatment for lung cancer: A longitudinal study. Chronobiol Int 34(4): 451-461.
This work is licensed under Creative Commons Attribution 4.0 License

To Submit Your Article Click Here:

Submit Article

\section{OSMOAJ}

DOI: $10.32474 /$ OSMOAJ.2018.02.000137

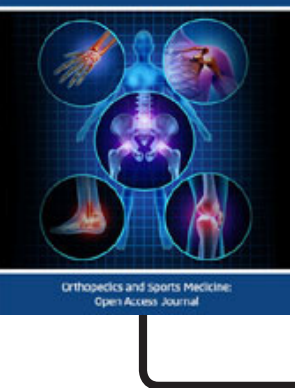

Orthopedics and Sports Medicine Open Access Journal

\section{Assets of Publishing with us}

- Global archiving of articles

- Immediate, unrestricted online access

- Rigorous Peer Review Process

- Authors Retain Copyrights

- Unique DOI for all articles 